Original Research Paper

\title{
Manufacturing of Granular Matrix with Diatomacious earth, Lime and Sugarcane Bagasse ash to Encapsulate Entomopathogenic Nematodes (Steinernema glaseri)
} \author{
${ }^{3}$ M. Reyes-Pérez, ${ }^{4}$ P. Montes-García and ${ }^{4}$ V.G. Jiménez-Quero \\ ${ }^{l}$ MSc Student in Conservation and Exploitation of Natural Resources, \\ Instituto Politécnico Nacional, CIIDIR Oaxaca, México \\ ${ }^{2}$ Universidad Politécnica de Francisco I. Madero, Hidalgo, México \\ ${ }^{3}$ Universidad Autónoma del Estado de Hidalgo, México \\ ${ }^{4}$ Instituto Politécnico Nacional, CIIDIR Oaxaca, México
}

${ }^{1,2}$ L.V. Bustamante-Espinosa, ${ }^{3}$ A. Castañeda-Ovando, ${ }^{3}$ J. Hernández-Ávila,

Article history

Received: 06-07-2019

Revised: 05-11-2019

Accepted: 17-01-2020

Corresponding Author:

V.G. Jiménez-Quero

Instituto Politécnico Nacional,

CIIDIR Oaxaca, México.

Email: vjimenezq@ipn.mx

vg.jimenezquero@gmail.com

\begin{abstract}
An alternative for pest control in corn production is the use of biopesticides formulated with entomopathogenic nematodes encapsulated in granular matrices. However, it has been observed that the granular matrices' lack of resistance to handling and transport causes their deterioration, therefore limiting their use. This study analyzes the use of lime and sugarcane bagasse ash as stabilizer additives in granular matrices made of diatomite earth in order to improve the survival rate of Entomopathogenic Nematodes. Six formulations were prepared and evaluated at 3, 12, 21 and 30 days of age. A total of 192 granular matrices were produced, 144 for axial compressive strength testing and 48 for the estimation of the survival rate of the nematodes. In order to carry out the last test, Steinernema glaseri nematodes were encapsulated. The results indicate that the granular matrices made with the combination of $88 \%$ diatomaceous earth plus $6 \%$ lime and 6\% sugarcane bagasse ash have adequate hardness (mechanical strength) for handling and transportation purposes; in addition, at 30 days of age the survival rate was the highest obtained when compared to the granular matrices of all tested formulations.
\end{abstract}

Keywords: Pest Control, Biopesticide, Pellet, Survival Rate, Recycling

\section{Introduction}

In Oaxaca, Mexico, corn has a fundamental role in the life of various communities' culture, traditions, economy and survival; however, several biotic and abiotic factors cause significant loss in corn production. Two of the main factors are soil infertility and insects, which together cause losses of approximately 20\% (García-Lara and Bergvinson, 2007). The plague of Phyllophaga spp attacks the radicular system of corn causing problems with germination, death of seedlings, loss of roots, rachitic plants and gooseneck-shaped stems, resulting in the surviving plants being stunted and yellowish.

There are different alternatives to minimize the damage to corn plants caused by pests. One alternative is integrated pest control, which takes into account chemical and biological control.

\section{Literature Review}

Among the first attempts to encapsulate Entomopathogenic Nematodes (EPN) was the use of a formulation containing activated carbon (Gauter, 2002). This formulation failed because of its high cost, the difficulties in manipulating the material and the lack of the matrix's stability at room temperature.

Kaya et al. (1987) encapsulated EPN in a polymeric matrix containing calcium alginate. This material is biodegradable, allowing the EPN to emerge from the capsules. The EPN lasted eight months in closed containers which were kept at $4{ }^{\circ} \mathrm{C}$ 
and lasted three to four months at room temperature. Nevertheless, for the implementation of this encapsulation method a previous application of sodium citrate is required to release the EPN from the alginate gel matrix. This last application and the use of several sieves and containers extended the extraction time and invalidated its implementation.

Connick et al. (1994) developed pellets with corn flour and encapsulated $S$. carpocapsae EPN with a survival time lower than eight weeks at $21^{\circ} \mathrm{C}$. However, the corn flour and the high humidity promoted the growth of fungus and bacteria. To solve the problem, the authors added $0.2 \%$ formaldehyde to the formulation of corn flour, bentonite, kaolin and turf and were able to store the EPN for 26 weeks at $21^{\circ} \mathrm{C}$. When the EPNs were released in a greenhouse, there resulted in $100 \%$ mortality of the wax moth (Galleria mellonella) and $90 \%$ mortality of the larvae corn rootworm and the potato beetle. However, formaldehyde is a suspected human carcinogen and proper safety measures should be employed in its handling and use.

Silver et al. (1995) patented an invention that relates to methods and compositions for storing and distributing pesticidal or herbicidal biological organisms, in particular entomopathogenic nematodes, for use as agricultural pest-control agents. More specifically, the invention concerns new methods for producing granules and formulating nematodes into such granules for prolonged storage and convenient application. The invention is directed to a storage composition of pesticidal- or herbicidal-viable biological organisms comprising a granule formed from a powder or mixture of powders which encase a soft core containing a quantity of viable biological organisms. The powder is preferably selected from the group consisting of silica, diatomaceous earth, hydroxyethyl cellulose, clay, pre-gelled clay, lignosulfonate, modified starch, pregelatinized starch, a super absorbent and a combination of one or more thereof. However, the patent does not provide the amounts or percentages of each of the powders used.

Navon et al. (1998) encapsulate $S$. riobrave in granules prepared with calcium alginate and corn starch that could control the $S$. littoralis larvae which eventually ate the granules. In another study, Navon et al. (2002) encapsulated EPN in calcium alginate to control Spodoptera littoralis and Helicoverpa armígera where the gelation time was prolonged to improve the gel for the disintegration of the mixture before the gelatinization.

The low Survival Rate (SR) of entomopathogenic nematodes caused by/during storage is a limiting factor for the mass production of biological pesticides (Grewal, 2002).

Given the great interest in the direct application of entomopathogenic nematodes in the field, Hiltpold et al.
(2012) developed a solution with a high concentration of $\mathrm{Ca}+2$ ions with the addition of alginate, resulting in the formation of a coat surrounding the liquid core; the core was prepared by mixing deionized water with gluconolactone and then $H$. bacteriophora EPN was added. The encapsulation was carried out by inverse esterification. The encapsulated EPN were more efficient than those sprayed with water in the control of the corn rootworm Diabrotica virgifera. This formulation represents a significant progress for the direct application in the field; however, the reduced number of nematodes per granule was a drawback for its distribution and mass application.

Another interesting study carried out by Antonyuk et al. (2005) described the behavior of the deformation and breakage of pellets obtained by a fluidized bed when subjected to compression. The pellets were prepared with $\mathrm{Al}_{2} \mathrm{O}_{3}$, Köstrolith synthetic zeolite and sodium benzoate $\left(\mathrm{C}_{6} \mathrm{H}_{5} \mathrm{COONa}\right)$. The authors determined the strength parameters of the pellets based on their size and mass by using a displacement-deformation diagram obtained from the application of an axial load, which is the characteristic of plastic and elastic materials.

Mendoza (2012) investigated the effect of the mechanical operations of pelleting and pellet hardness on survival time in entomopathogenic nematodes. Nematodes of the species Steinernema glaseri were encapsulated in diatomaceous earth and attapulgite in different proportions. The mechanical method of pelletization was proposed by Espinosa (2005); in that study pellets were stored at room temperature of 17 $29^{\circ} \mathrm{C}$. The hardness test was conducted under the standard ASAE 363.3 (ASAE, 1993) and the counting of the surviving nematodes was conducted daily by the method of Chen and Glazer (2005). The results show that the mechanical encapsulation process doubles the time of survival of the nematodes reported for those manually processed (Girón, 2008). The survival of nematodes in the first three days was $100 \%$, which gradually decreases. The best results were obtained with pellets made from diatomaceous earth, Celite 209 and cactus mucilage, posting $22 \%$ mortality at day eight.

Based on this finding, the objective of this study was to evaluate the effect of the addition of stabilizers on the survival rate of EPN embedded Granular Matrices (GM). A series of experiments were carried out considering several combinations of diatomaceous earth, calcium hydroxide (lime) and sugarcane bagasse ash to manufacture GMs by the pellet rolling method. The GMs were tested under axial compressive strength. Entomopathogenic Nematodes (EPN) were encapsulated in the various GMs and the Survival Rates (SRs) at two ages were investigated. 


\section{Materials and Methods}

To evaluate the effect of the addition of stabilizers on the survival rate of EPN embedded in GMs', a series of experiments were carried out. First, formulations were designed and materials were characterized. Then the GMs were prepared and tested on compression. Next, the GMs were again prepared with the same formulations and embedded EPN. Finally, the EPN SRs were estimated In vitro testing. In a second stage of this research the effectiveness of EPN to control Phyllophaga spp (In situ) in corn crops.

\section{Design of the Granular Matrices}

The materials to be used for the preparation of GMs must be neither toxic for people nor cause the death of the EPN to be encapsulated in it (NIMF, 2005). For this reason, in preparing the GMs it was decided to use diatomaceous earth as a reference material (D) (Connick et al., 1994; Silver et al., 1995). The materials proposed to stabilize the GMs were calcium hydroxide (C) and Sugarcane Bagasse Ash (SCBA), which have been successfully used to stabilize soils in compressed blocks (Alavéz-Ramírez et al., 2012). Regarding the addition of $\mathrm{C}$ as a stabilizer, a maximum value of $10 \%$ was used to prevent the alteration of soil fertility (NOM-021-SEMARNAT, 2000).

With respect to the addition of SCBA in the GMs, a maximum value of $6 \%$ was decided to maintain the Basicity Index of the soil, which is necessary for the survival of the EPN (Imbert and Villar, 2006). The ages of maturity were chosen considering that after 48 hours the anhydrobiotic state of the EPN begins, causing chemical changes which in turn decrease the activity and the oxygen consumption rate of the EPN (Bedding and Butler, 1994). In addition, Grewal (2002) reported that 21 and 30 days are critical stages for the survival of EPN. The SRs of EPN encapsulate in pellets at room temperature has not been reported.

Based on the previous recommendations, a first full $6 \times 4$ factorial design was implemented, considering as factors the type of formulation used to fabricate the GMs and the age of maturity. For the preparation of the GMs The following combinations of ingredients were used: one formulation with $100 \%$ diatomaceous earth (D) was prepared, three formulations containing the combination of D plus 6, 8 and $10 \%$ calcium hydroxide (C) and two formulations with the combination of $\mathrm{D}+\mathrm{C}$ plus 3 and 6\% Sugarcane Bagasse Ash (SCBA). The criteria for the proportioning of the materials for the fabrication of the pellets was by partial replacement of the raw material and by weight. The ages of maturity at which the GMs were tested were 3,12, 21 and 30 days. The response variables were the Compressive Strengths (CS) estimated at the four ages of maturity with six replicates. A second full $6 \times 2$ factorial design was implemented considering as factors the type on formulation used to fabricate the GMs and two ages of maturity. For the preparation of the GMs the same combinations of ingredients were used as in the first design. The response variables were the Survival Rates (SR) which were estimated at 21 and 30 days with four replicates. Details of the variables and levels of two factorial designs are shown in Table 1.

\section{Description and Characterization of Materials}

The diatomaceous earth Celite $209^{\odot}$ (D) used is extracted from Zacoalco de Torres, Jalisco, Mexico. The Calcium hydroxide (C) was commercially readily available in Valles Centrales, Oaxaca, Mexico. The Sugarcane Bagasse Ash (SCBA) was obtained from an open dump which belongs to the sugar mill "Constancia," located in Tezonapa, Veracruz, Mexico. The SCBA is a residue resulting from the burning of bagasse in boilers in the sugarcane/alcohol industry and deposited at open dumps. After the SCBA was collected, it was sun dried and sieved through a sieve No. 4 (4.75 $\mathrm{mm})$ ASTM, then homogenized and sieved again through a sieve No. $200(75 \mathrm{~mm})$ for four minutes.

The EPN used were the species Steinernema glaseri from an original CEPA from the Entomology Laboratory at the University of California, Davis (USA). For the EPN production, G. mellonella larvae (host) at the last instar were used as a host. The in vitro mass production and storage of the EPN was in accordance with the recommendation of Kaya and Stock (1997).

The chemical compositions of the materials were studied by the gravimetric and ICP methods using a Perking Elmer Optima $8300^{\circledR}$ spectrometer. The mineral phases of the materials were identified using XR diffraction using an INEL, model EQUINOX $2000^{\circledR}$. The particle-size distributions and pore volumes were determined by Laser Ray Diffraction using a LS13320 ${ }^{\circledR}$, while the specific surface areas were estimated by the BET method using ASAP 2020 Micrometrics ${ }^{\circledR}$ equipment. Finally, the morphologies of the materials were observed using a JEOL6300 JSM ${ }^{\circledR}$ scanning electron microscope.

Table 1: Testing layout

\begin{tabular}{llll}
\hline Factorial design & Factor & Description & Response \\
\hline $6 \times 4$ & Formulation & $100 \mathrm{D}, 94 \mathrm{D}+6 \mathrm{C}, 92 \mathrm{D}+8 \mathrm{C}, 90 \mathrm{D}+10 \mathrm{C}$, & Hardness \\
& & $94 \mathrm{D}+3 \mathrm{C}+3 \mathrm{SCBA}, 88 \mathrm{D}+6 \mathrm{C}+6 \mathrm{SCBA}$, & Work of compression (WOC) (N x mm) \\
& Age (Days) & $3,12,21,30$ & \\
& Formulation & $100 \mathrm{D}, 94 \mathrm{D}+6 \mathrm{C}, 92 \mathrm{D}+8 \mathrm{C}, 90 \mathrm{D}+10 \mathrm{C}$, & Survival Rate (SR) $(\%)$ \\
& & $94 \mathrm{D}+3 \mathrm{C}+3 \mathrm{SCBA}, 88 \mathrm{D}+6 \mathrm{C}+6 \mathrm{SCBA}$, & \\
& Age (Days) & 21,30 &
\end{tabular}

Notes: D = Diatomaceous Earth, $\mathrm{C}=$ Calcium Hydroxide, SCBA = Sugarcane Bagasse Ash 


\section{Preparation and Characterization of the Granular Matrices}

The procedure for the production of the GMs was based on the principle discussed by Mendoza (2012) and Matadamas-Ortiz et al. (2014). The quantities of the materials for the preparation of the GMs were determined by the mass of the diatomaceous earths according to each formulation proportion shown in Table 1.

The ingredients were dry mixed until a homogeneous powder was obtained and then the powder was poured in an inverted frustum which had a lid at the bottom. Then, $200 \mu \mathrm{L}$ of deionized water was added to the powder at the top of the frustum and the lid was removed. The water added to the powder agglutinated some particles and due to gravity small quasi-spherical shaped granules, called nuclei, were formed during their fall, according to the fluidized bed principle. Next, the nuclei were rolled on a rotating Archimedes spiral plate for 45 seconds in order to continue with the growing and consolidation of the GMs.

Figure 1 shows the appearance of the GMs prepared with the six formulations. The GMs obtained were not uniform in size, the diameters ranging between 10 and $16 \mathrm{~mm}$. This effect was more evident in the formulations containing $\mathrm{C}$ and SCBA.

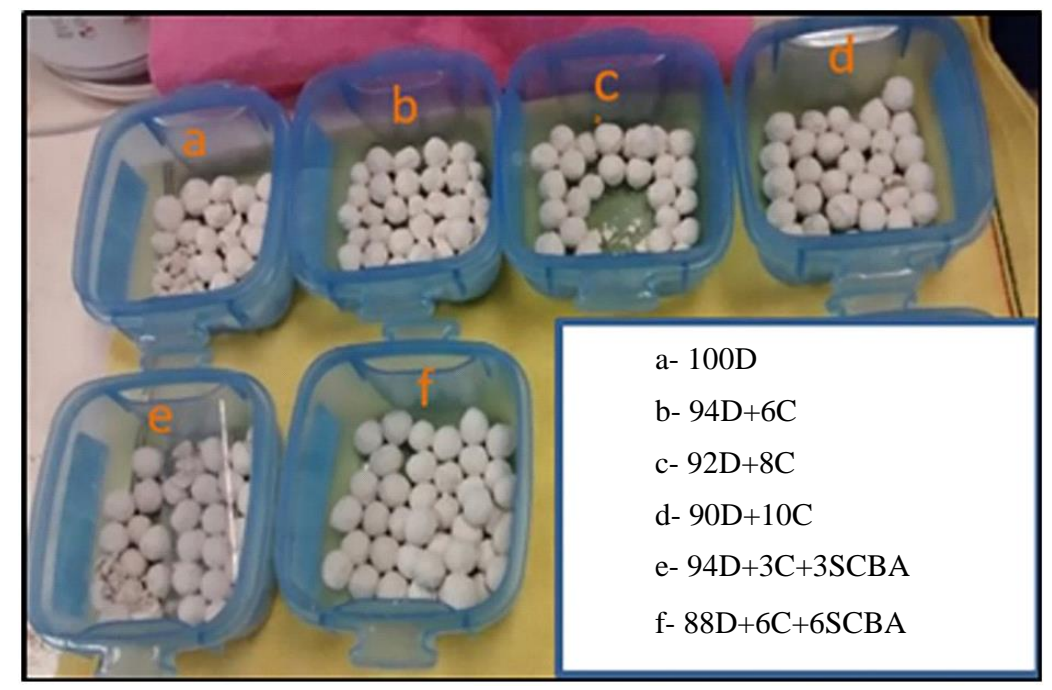

Fig. 1: Appearance of the granular matrices

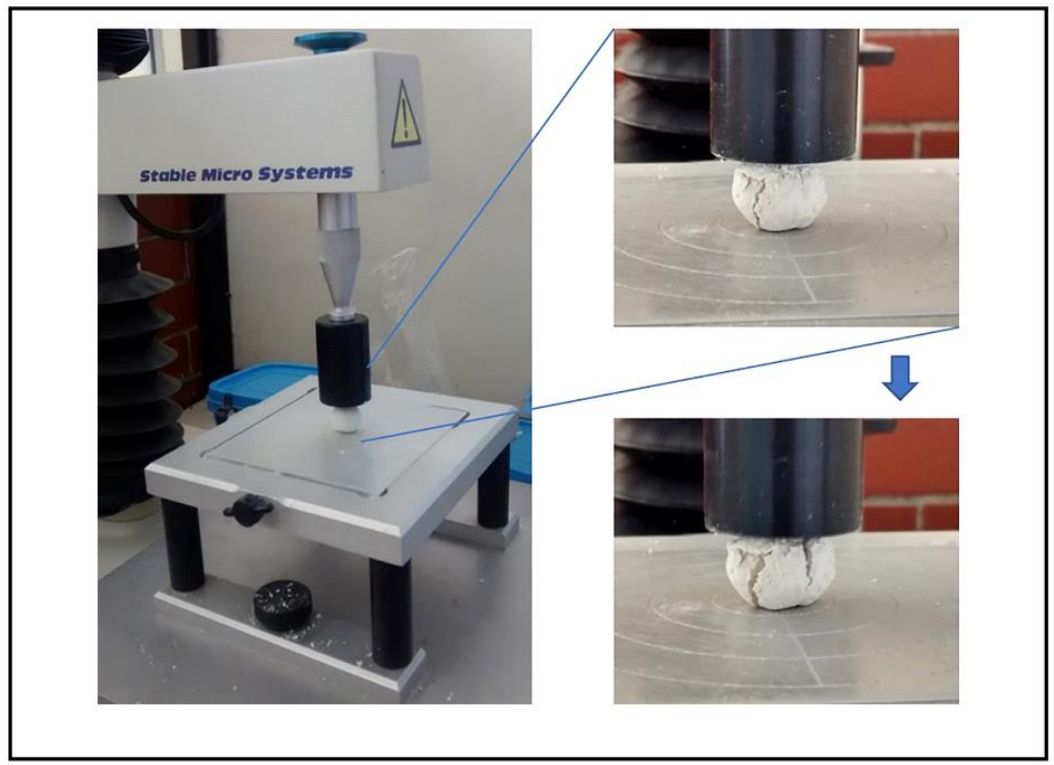

Fig. 2: Set-up for the compressive load applied to the GMs 
The mechanical strength of the GMs was investigated by applying a monotonic compression load to each GM until a 6-mm displacement was reached. To do this, a TA XT2i Stable Micro System ${ }^{\circledR}$ texturometer was used (Fig. 2). The accessories and operating parameters were a P1R probe of up to $2 \mathrm{kN}$, a pre-test velocity of 5 $\mathrm{mm} / \mathrm{s}$, a displacement speed of the probe of $0.01 \mathrm{~mm} / \mathrm{s}$, a return speed of the probe of $10 \mathrm{~mm} / \mathrm{s}$, a breaking distance of $10 \mathrm{~mm}$, a load $4.99 \mathrm{~N}$, a test time of 5 seconds, a sensibility of the equipment $0.05 \mathrm{~N}$ and a range of data acquisition of 500 pps. Texture Expert $32^{\circledR}$ software was used for the acquisition and processing of the 12,005 data recorded during each test. Six replicates were tested for each formulation.

The fracturability and hardness of the GMs were determined from the load vs. displacement curves obtained from the compression test; the area under the curve, which is usually termed the Work of Compression/Compaction (WOC), was calculated by numerical integration using MatLab R2012 $\mathrm{a}^{\circledR}$ software for all the GMs. The GMs were not uniform in size and the diameters ranged between 10 and $16 \mathrm{~mm}$. This fact caused some curves to be more extended than others, despite having already reached the maximum load. Therefore, to calculate the WOC for all the GMs, a deformation of $6.0 \mathrm{~mm}$ was used.

\section{Reproduction and Encapsulation of the EPN}

The reproduction process of the EPN implemented was that proposed by Kaya and Stock (1997), Fig. 3. The G. mellonella larvae (host) were soaked in $55^{\circ} \mathrm{C}$ deionized water for $15 \mathrm{~s}$, then soaked in $15^{\circ} \mathrm{C}$ deionized water for 15 $\mathrm{s}$ to prevent the larvae reaching the pupal stage and to decrease their resistance to the EPN infestation.

The larvae were laid on a Petri box where previously had been placed a filter paper $(5 \mathrm{~mm}$ in diameter, 80 $\mathrm{g} / \mathrm{m}^{2}$ weight, $0.17 \mathrm{~mm}$ thick and pore size of 14 to 18 $\mu \mathrm{m})$. Then $200 \pm 10 \mathrm{EPN}$ per each larva were inoculated using $20 \mu \mathrm{L}$ of distilled water in order to produce moisture of $10 \mathrm{~g} / \mathrm{m}^{3}$ in the filter paper to ease the mobility of the EPN and consequent infection of the larvae.

After five days following the infestation, the larvae were carefully transferred to $15 \times 8 \mathrm{~cm}$ white traps which contained $45 \mathrm{~mL}$ of distilled water. When the EPN emerged from the larvae, they moved through the wet filter paper until reaching the distilled water where they were collected.

The water used at all times for the manipulation of the EPN was $\mathrm{CO}_{2}$-free to prevent any kind of damage to the EPN during their conservation (Chen and Glazer, 2005). The EPN was stored at $6-8^{\circ} \mathrm{C}$ for a week; after this storage time, the EPN were available for encapsulation.

Prior to the encapsulation in the GM, the EPN were acclimated at $23 \pm 6^{\circ} \mathrm{C}$ during $24 \mathrm{~h}$ (Chen and Glazer, 2005). Then, a solution containing $100 \pm 10$ EPN per 200 $\mu \mathrm{L}$ of water was prepared using the volumetric dissolution method in accordance with the recommendation of Petersen and Willis (1972). By the repeated water dropping technique of $10 \mu \mathrm{L}$, the amount of EPN in the solution is determined; this procedure was repeated until the required concentration was achieved (Girón, 2008).

The solution was continuously stirred to keep a constant homogeneous concentration of $100 \pm 10$ EPN and in this way prevent the precipitation of the EPN caused by the different densities.

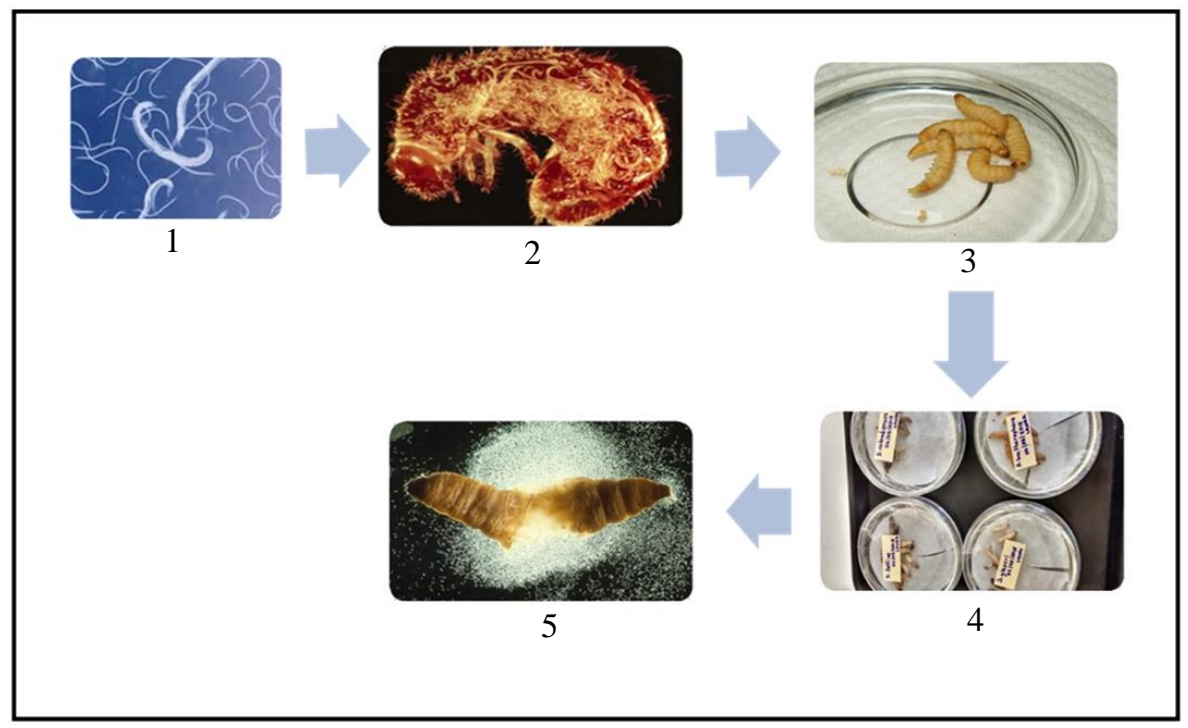

Fig. 3: The reproduction process of the EPN (1 CEPA, 2 CEPA activation, 3 G. mellonella larvae (host), 4 Infection of the larvae, 5 EPN emerged) 
Once the solution was prepared, the production of pellets $(\mathrm{GM}+\mathrm{EPN})$ following the procedure previously described was carried out for the six formulation proportions established.

\section{Estimation of the EPN Survival Rates (SR)}

To estimate the EPN SR, the pellets were placed in a $9 \mathrm{~cm}$ Petri box and $10 \mathrm{ml}$ of distilled water were added to provide the moisture required by the EPN to recover mobility. The excess water served for the EPN solution-making. A micropipette was used to take a 200 $\mu \mathrm{L}$ sample from the EPN solution and place it in a stereoscopic microscope to count the live and dead EPN. The microscope used for the counting was an Olympus $^{\circledR}$ with a 0.2 opening, a resolution of 600 pairs of lines per mm and a 30x zoom.

The identification of the live EPN is straight forward because they move naturally or when stimulated with a needle. The EPN was counted using the method proposed by Chen and Glazer (2005). Once the counting was concluded, the remaining sample was returned to the original solution and the counting process was repeated five times for each pellet. The EPN counting was performed at 21 and 30 days, according to the experimental design.

\section{Results}

\section{Characterization of the Materials}

The results of the chemical analysis of the materials (Table 2) indicate that the main compounds present in D and SCBA are silica and alumina, with low traces of $\mathrm{CaO}$ and $\mathrm{MgO}$. Similar results were reported by Wen-Tien et al., 2004; Galal Morsy, 2010; Chargas-Cordeiro et al., 2009. The sum of major oxides is higher than $70 \%$; therefore, the materials have pozzolanic potential (ASTM, 2012) and can react in an alkaline environment created by C (Malhotra and Ramezanianpour, 1994).

Figure 4 shows that $\mathrm{D}$ exhibit an amorphous halo between $15-35^{\circ} 2 \theta$ angle, this coincides with findings by Wen-Tien et al., 2004; Bahurudeen et al., 2015; Wen-Tien et al., 2006.

Figure 4 also confirms that the D has orthoclase and quartz coinciding with what was reported by Liu et al., 2014; Wen-Tien et al., 2006 and the SCBA has quartz, cristoballite, calcite and magnetite, corroborating what was found by Martirena, et al., 998 .

Table 2: Chemical compositions of the materials (\%)

\begin{tabular}{|c|c|c|c|}
\hline Compound & $\mathrm{D}$ & $\mathrm{C}$ & SCBA \\
\hline $\mathrm{SiO}_{2}$ & 83.95 & 0.28 & 59.56 \\
\hline $\mathrm{Al}_{2} \mathrm{O}_{3}$ & 3.11 & $<0.03$ & 13.62 \\
\hline $\mathrm{Na}_{2} \mathrm{O}$ & $<0.03$ & $<0.03$ & $<0.03$ \\
\hline $\mathrm{MgO}$ & $<0.005$ & 0.40 & 1.13 \\
\hline $\mathrm{K}_{2} \mathrm{O}$ & 0.12 & $<0.09$ & 3.25 \\
\hline $\mathrm{CaO}$ & 0.34 & 72.76 & 2.22 \\
\hline $\mathrm{Fe}_{2} \mathrm{O}_{3}$ & 1.62 & $<0.10$ & 5.52 \\
\hline $\mathrm{FeO}$ & $<0.01$ & $<0.01$ & 0.7 \\
\hline $\mathrm{P}_{2} \mathrm{O}_{5}$ & $<0.06$ & $<0.06$ & 0.96 \\
\hline $\mathrm{MnO}$ & 0.01 & $<0.003$ & 0.33 \\
\hline LOI & 11.13 & 26.32 & 10.78 \\
\hline$\Sigma \mathrm{SiO}_{2}+\mathrm{Al}_{2} \mathrm{O}_{3}+\mathrm{Fe}_{2} \mathrm{O}_{3}$ & 88.68 & -- & 78.7 \\
\hline
\end{tabular}

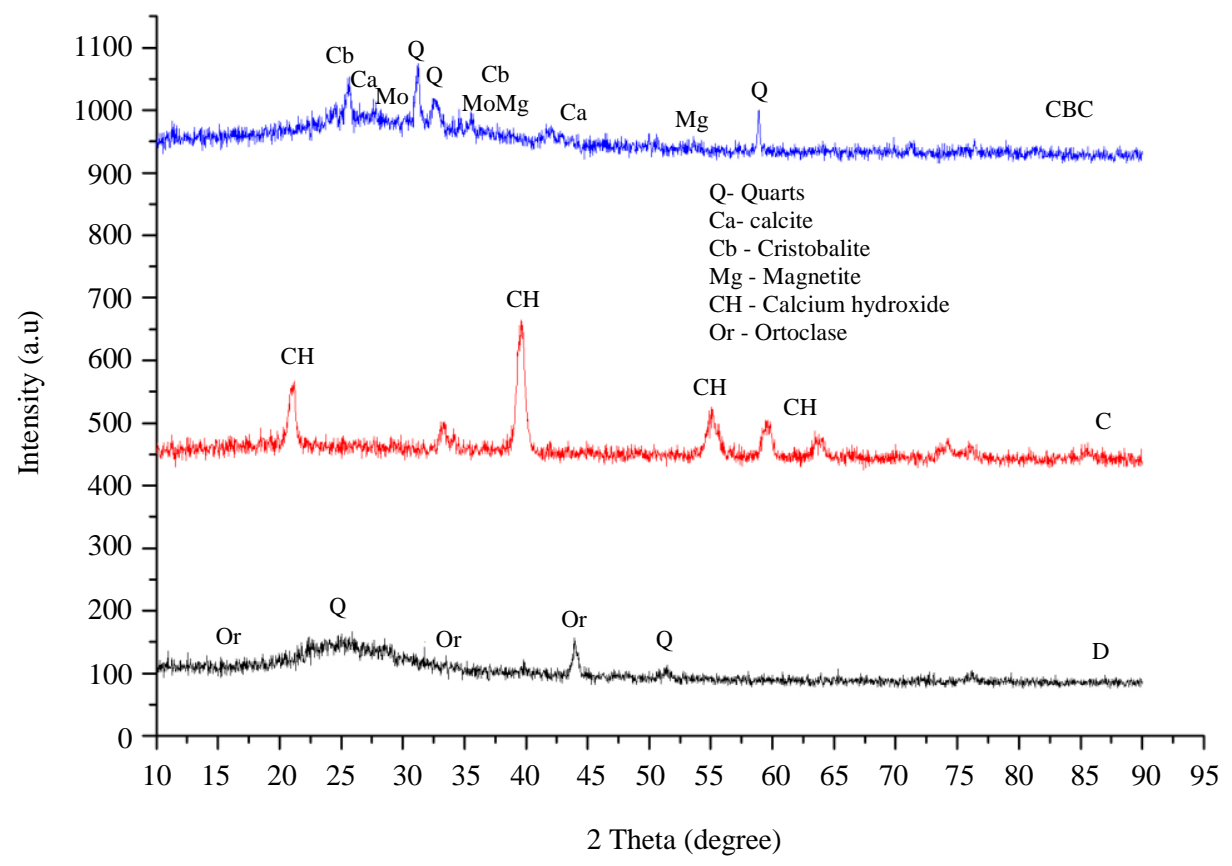

Fig. 4: Patterns of the mineral phases of the materials 


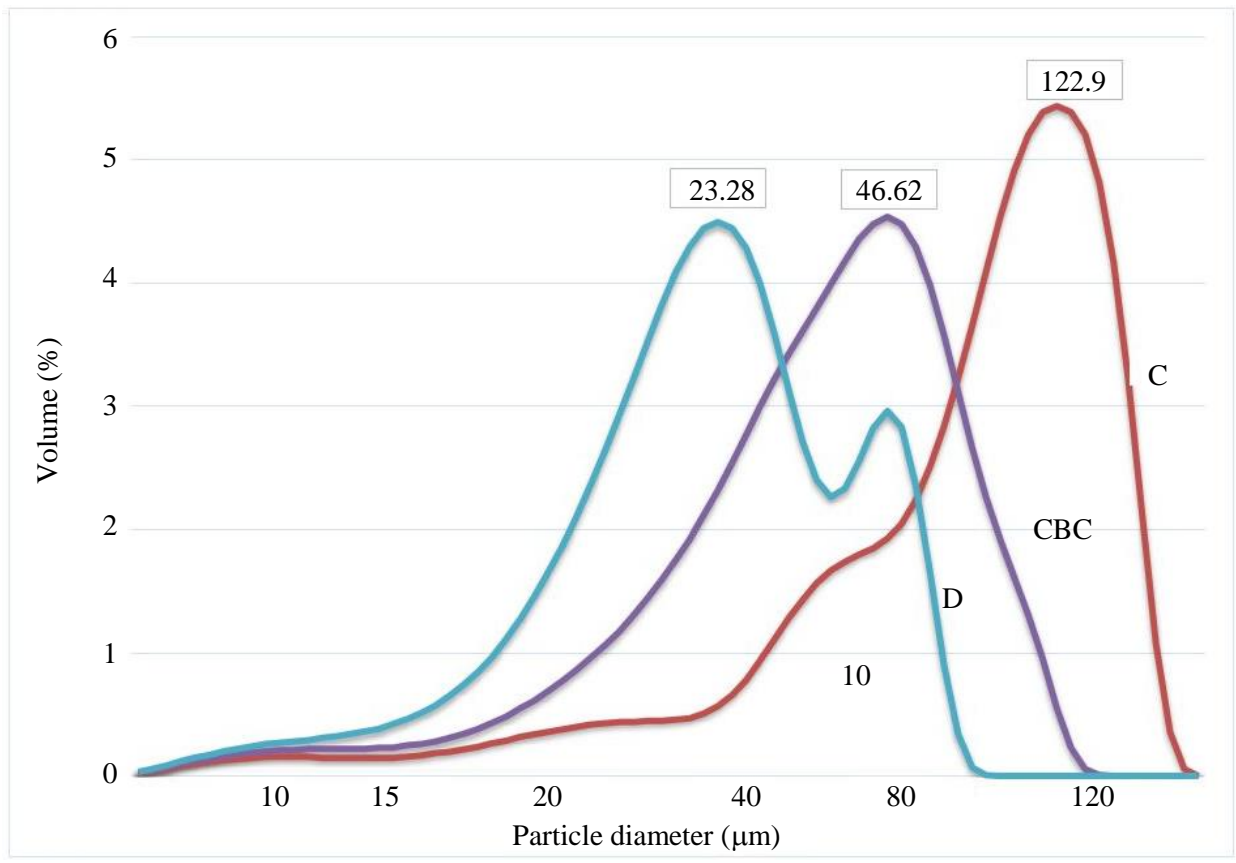

Fig. 5: Particle sizes distributions of the materials $(\mu \mathrm{m})$

Figure 5 shows the particle sizes of the materials; it is important to note that the material's particle size has a direct effect on its reactivity. Between $10 \%$ and $30 \%$ of particles of D and SCBA have an average size of $45 \mu \mathrm{m}$, which can favor their pozzolanic reaction with C (Chargas-Cordeiro et al., 2009). D particles are finer than SCBA particles because they are subjected to crushing and grinding, whereas SCBA is only subjected to sieving, which has been proven to increase its reactivity (Bahurudeen et al., 2015; Ganesan et al., 2007).

There is a large difference between particle-size distributions with D50 values ranging from 8.81 to 115.9 $\mu \mathrm{m}$. The distributions of particle sizes are complex, because the $\mathrm{D}$ distribution is multimodal.

The differences in particle sizes condition the relationship between the cohesive forces, which depend on the materials' surfaces and inertial and gravitational forces, which in turn depend on their mass. This means that small particles have larger cohesion forces.

In Figure 6 the different shapes and sizes of the materials are observed. For example, the D particles show coscinodisophyceae (radial symmetry) and fragilariophyceae (bilateral symmetry, or sternum pseudolateral) shapes with open pores which allow accommodating solids, Fig. 6a; coinciding with what was reported by Sun et al., 2013. In C, crystals of calcium hydroxide which are isolated or forming quasispherical agglomerates can be observed, Fig. 6b. The SCBA is a heterogeneous material with particles of different sizes and shapes, Fig. 6c, Driemeier et al.,
(2011) published similar micrographs. The particles can be classified as prismatic, spherical and fibrous. According to Batra et al., (2008) that prismatic particles consist mainly of $\mathrm{Si}$ and $\mathrm{O}$, while spherical particles consist of $\mathrm{Si}, \mathrm{O}, \mathrm{Na}, \mathrm{K}, \mathrm{Al}, \mathrm{Mg}$ and $\mathrm{Ca}$; while Umamaheswaran and Batra, (2008) said that fibrous particles consist mainly of carbon.

\section{Characterization of Granular Matrices}

\section{Characterization of Hardness of the GMs}

The average compressive strength results of the GMs prepared with the different combinations of D+C+SCBA are presented in Fig. 7 (Increase in strength over time).

The results of the GMs tested indicate that for all test ages the addition of $\mathrm{C}$ has a significant effect on the improvement of the strength of the pellets (Fig. 7); standing out is the GM with $8 \% \mathrm{C}$, which increased the strength up to $380.3 \%$ at 30 days (Fig. $7 d$ ). The compressive strengths of the GMs prepared with $\mathrm{D}+\mathrm{C}+\mathrm{SCBA}$ were higher than those for only $\mathrm{D}$, except the formulation $88 \mathrm{D}+6 \mathrm{C}+6 \mathrm{SCBA}$ which had a strength $48.7 \%$ lower than $\mathrm{D}$ at 3 days (Fig. 7a).

The compressive strength of GMs prepared with the formulations $\mathrm{D}+\mathrm{C}$ were higher than the strength of GMs prepared with the D+C+SCBA formulation; however, when the formulation with $94 \mathrm{D}+6 \mathrm{C}$ was compared with the 94D+3C+3SCBA and $88 \mathrm{D}+6 \mathrm{C}+6 \mathrm{SCBA}$ formulations this effect was reversed; the compressive strength was $14.7 \%$ and $26.1 \%$ lower respectively (Fig. 7a and 7d). 
L.V. Bustamante-Espinosa et al. / American Journal of Agricultural and Biological Sciences 2020, Volume 15: 8.22 DOI: 10.3844/ajabssp.2020.8.22

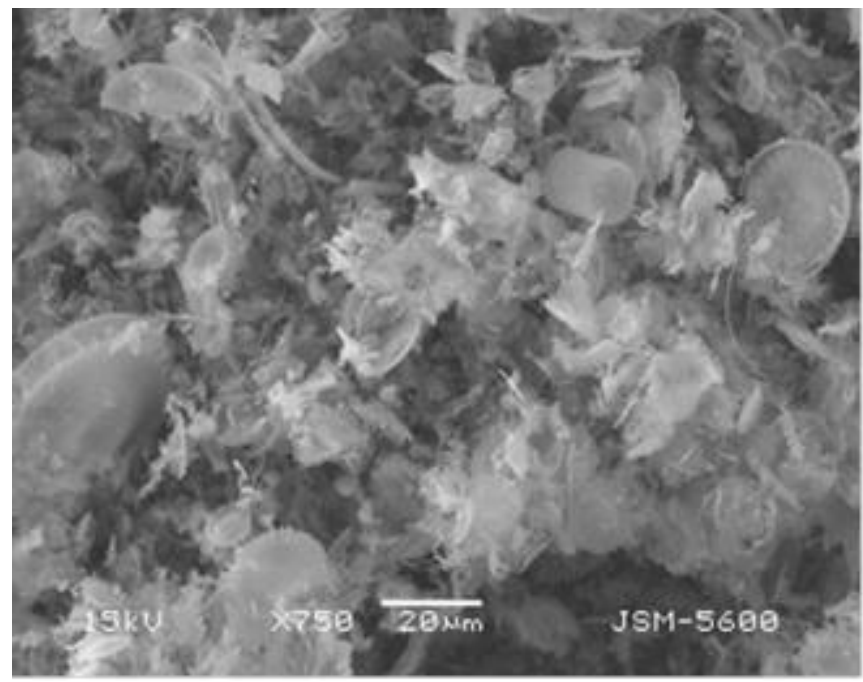

(a)

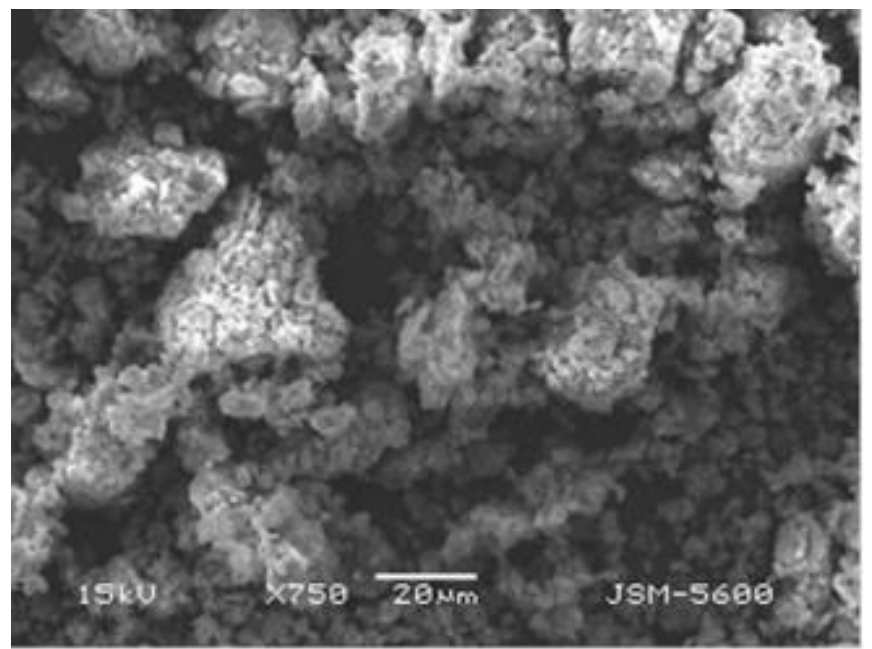

(b)

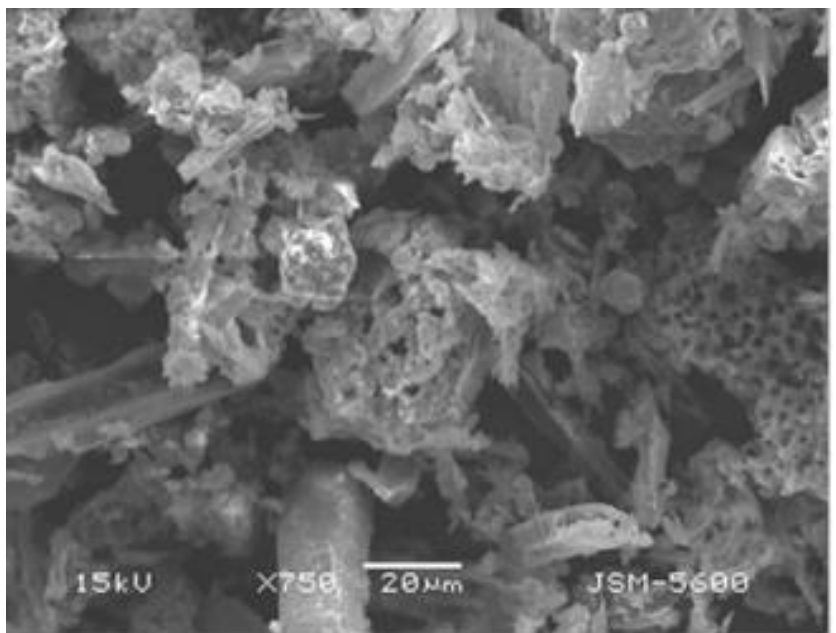

(c)

Fig. 6: Morphology of the materials 
L.V. Bustamante-Espinosa et al. / American Journal of Agricultural and Biological Sciences 2020, Volume 15: 8.22

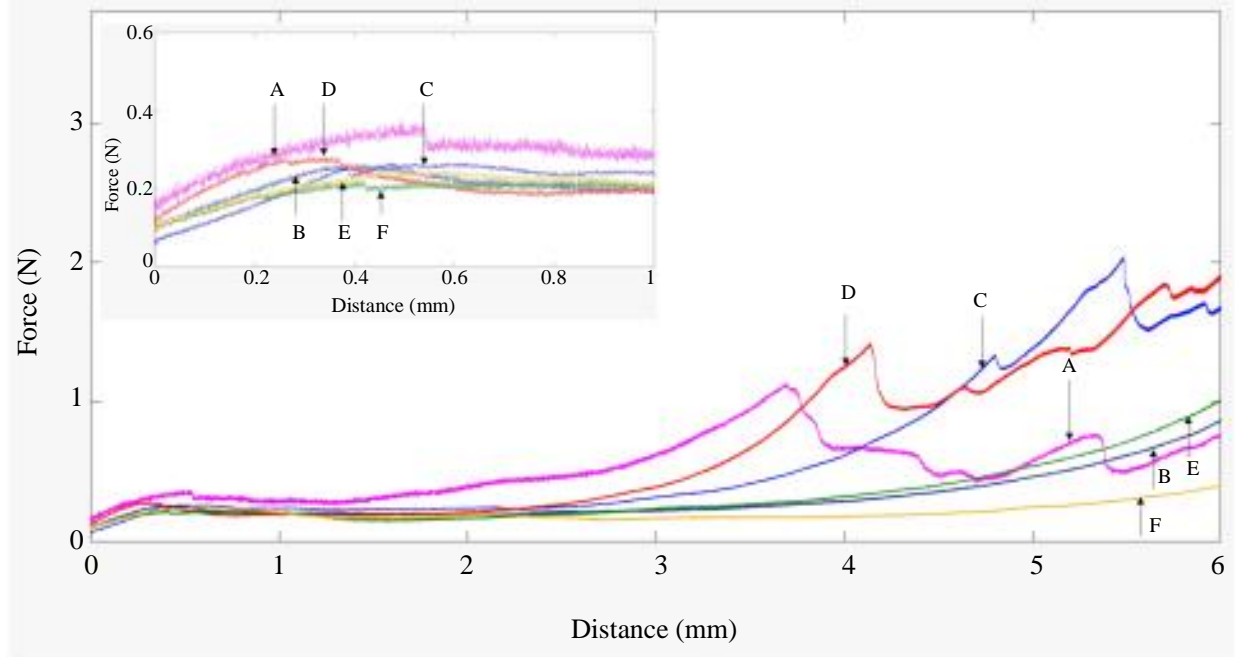

(a)

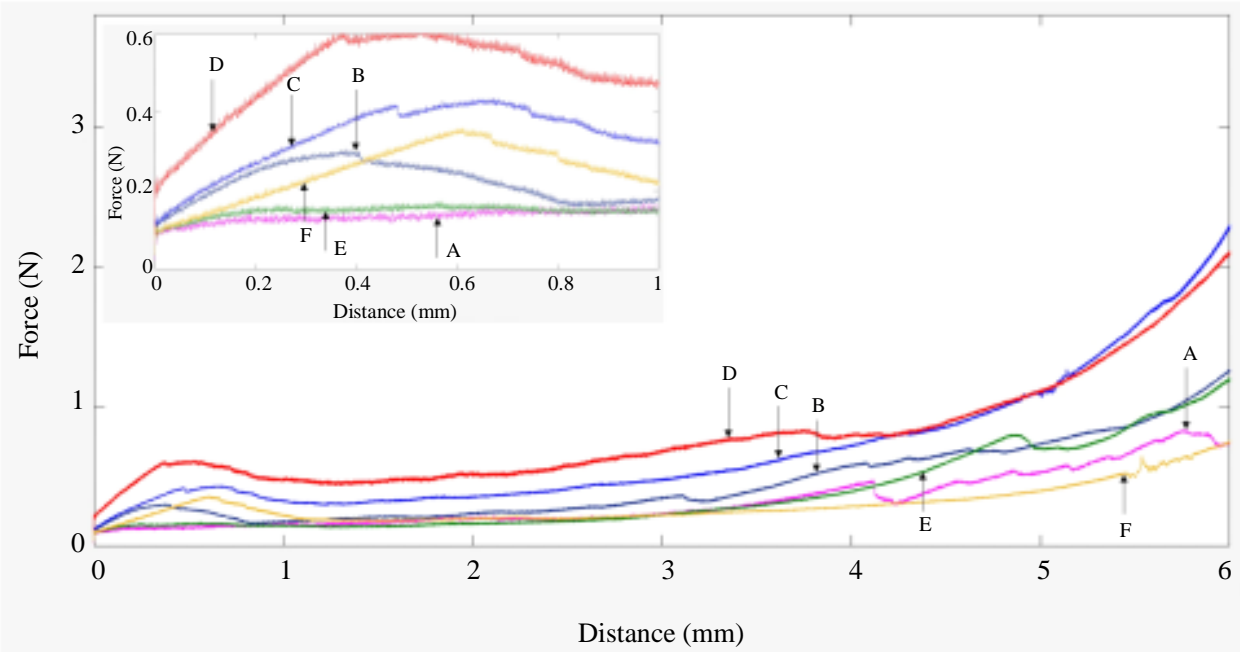

(b)

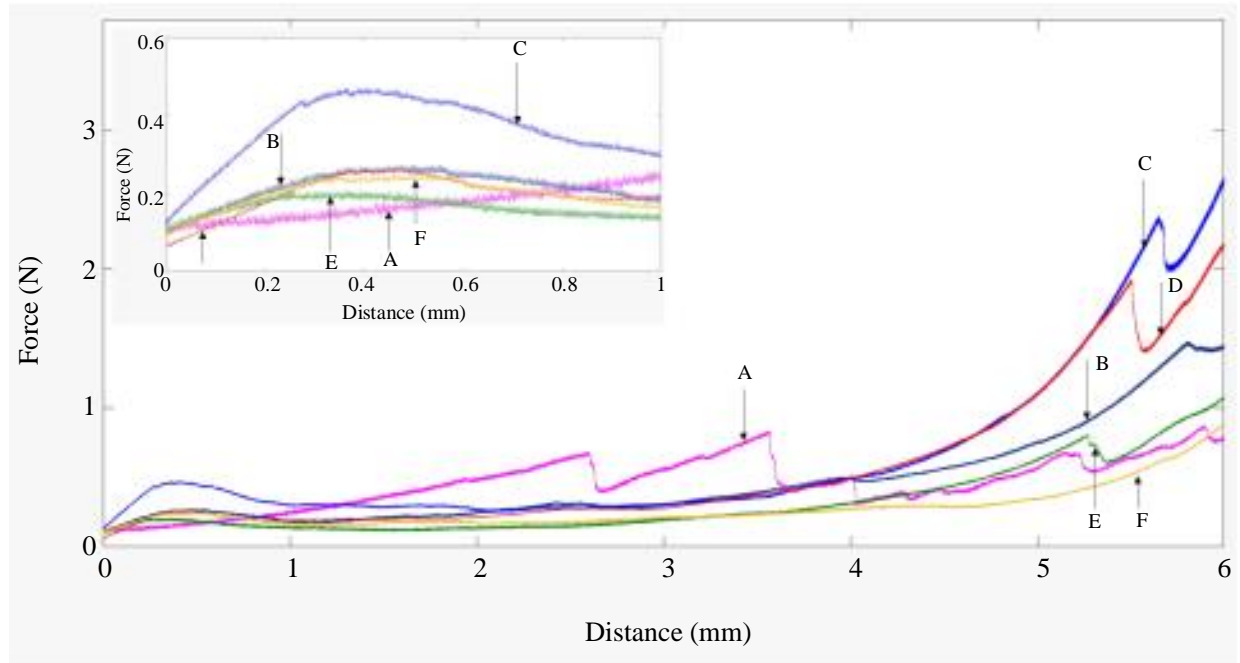

(c) 


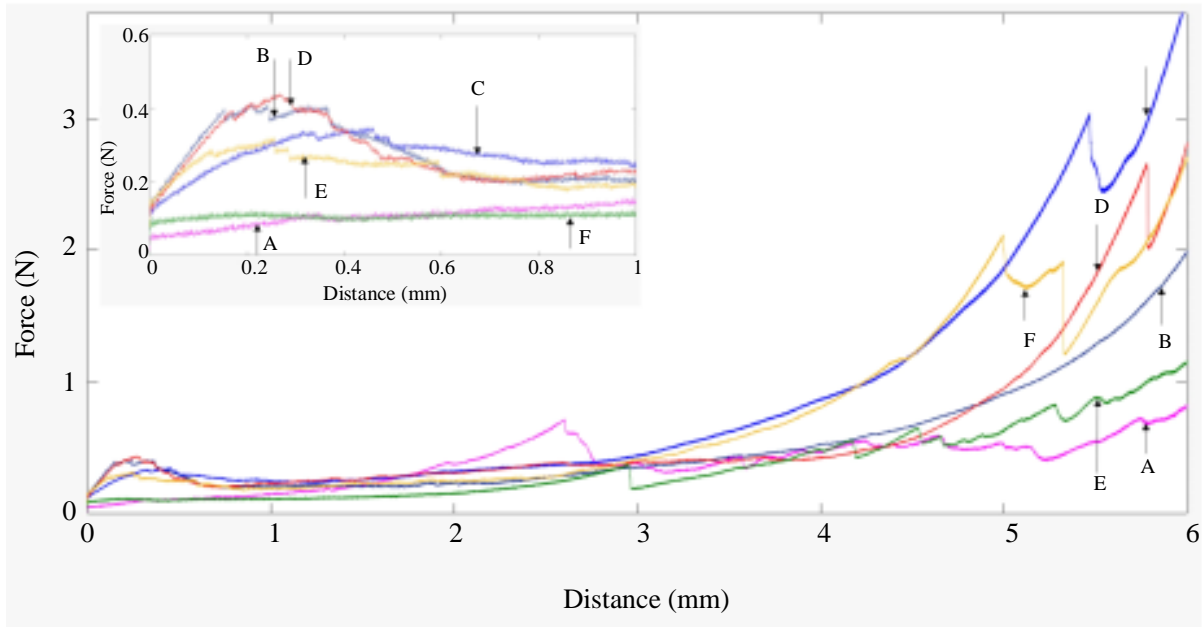

(d)

Fig. 7: Summary of compressive strengths of GMs based on D at different ages

All the graphs in Figure 7 identify a well-defined region between 0 and $1 \mathrm{~mm}$ of displacement, with this region corresponding to the yield of the materials showing a quasi-elastic behavior (Antonyuk et al., 2005). For a better analysis, the magnifications are presented. The magnifications show that the GMs manufactured with the combination of $\mathrm{D}+\mathrm{C}$ have higher stiffness than formulations containing the combination $\mathrm{D}+\mathrm{C}+\mathrm{SCBA}$; they also show that the latter has a higher stiffness than those prepared with only D.

The results of the compressive strength of the GMs tested at 3 days (Fig. 7a) show that with a higher percentage of $\mathrm{C}$ greater strength is obtained. The strength of GMs prepared with $90 \mathrm{D}+10 \mathrm{C}$ was $149.96 \%$ higher than those for only D and was $87.1 \%$ and $381.3 \%$ higher than formulations 94D+3C+3SCBA and $88 \mathrm{D}+6 \mathrm{C}+6 \mathrm{SCBA}$ respectively.

The results of the compressive strength of the GMs tested at 12 days (Fig. $7 b$ ) show the formulation 92D+6C generated the highest resistance values of all formulations. In this case the strengths of the GMs with $6 \mathrm{C}$ was higher by $208.2 \%$ with respect to $\mathrm{C}$. When compared with the formulations $94 \mathrm{D}+3 \mathrm{C}+3 \mathrm{SCBA}$ and $88 \mathrm{D}+6 \mathrm{C}+6 \mathrm{SCBA}$, the differences were $92.5 \%$ and $207.0 \%$ respectively.

At 21 and 30 days, the strength of GMs prepared with $92 \mathrm{C}+8 \mathrm{C}$ was higher than other formulations, Fig. $6 \mathrm{c}$ and $6 \mathrm{~d}$, respectively.

Nevertheless, it is worth noticing that the latter showed an increase of $20 \%$ with respect to the $94 \mathrm{D}+6 \mathrm{C}$ and $90 \mathrm{D}+10 \mathrm{C}$ formulations.

At 30 days of age the yield region of the materials mentioned in the previous paragraphs is also well defined; however, at this age the yield region differs from the trend observed at previous ages because increases in the elastic range of deformation are observed (Antonyuk et al., 2005). This behavior can be the result of the loss of moisture of the GMs and of the conformation of the GMs structures in layers.

\section{Characterization of Work of Compression (WOC)}

The results of the calculation of the WOC for the GMs prepared with the D+C+SCBA formulations are shown in Fig. 8. The WOC needed to deform the GMs prepared with only the $\mathrm{D}$ formulation decreased from 3 to 12 days. This can be associated with the loss of moisture of the GMs (Bika et al., 2001), for the following two ages shows similar values, as the D particles do not react with the mixing water, coinciding with what was reported by Coury and Aguiar, (1995) and at the beginning of the experiment the particles are kept together mostly by physical effects.

The results of WOC also showed that the addition of C significantly improved the strength of the GMs prepared with only D. This was evident especially for 8 and $10 \% \mathrm{C}$. The increase in the WOC is the result of the agglomeration of the $\mathrm{D}$ particles caused by the $\mathrm{C}$. Another reason for the improvement of the strength of the GMs is the chemical reaction between the ingredients of the formulation forming new cementing compounds as time progresses (Karatepe et al., 2004).

The WOCs for the GMs prepared with the combinations of $\mathrm{D}+\mathrm{C}+\mathrm{SCBA}$ were lower than the estimated for the GMs prepared with only the D formulation; however, the formulation $88 \mathrm{D}+6 \mathrm{C}+6 \mathrm{SCBA}$ at 30 days was higher than the formulation with only D. Similarly, in the results of WOC for the GMs containing $\mathrm{C}$, the WOCs increase over time, although it is less marked than for the GMs prepared with $\mathrm{D}+\mathrm{C}$. In this case there was a difference when adding 6\% SCBA instead of $3 \%$ at 30 days. The improvement of the GMs by the addition of C and SCBA can be attributed to physical effects, as the probable reaction between the amorphous silica in D and SCBA with C is more likely to occur at longer ages than those considered in the present study, similar results were reported by Martirena et al., (1998) and Frías et al., (2011). 
L.V. Bustamante-Espinosa et al. / American Journal of Agricultural and Biological Sciences 2020, Volume 15: 8.22 DOI: 10.3844/ajabssp.2020.8.22

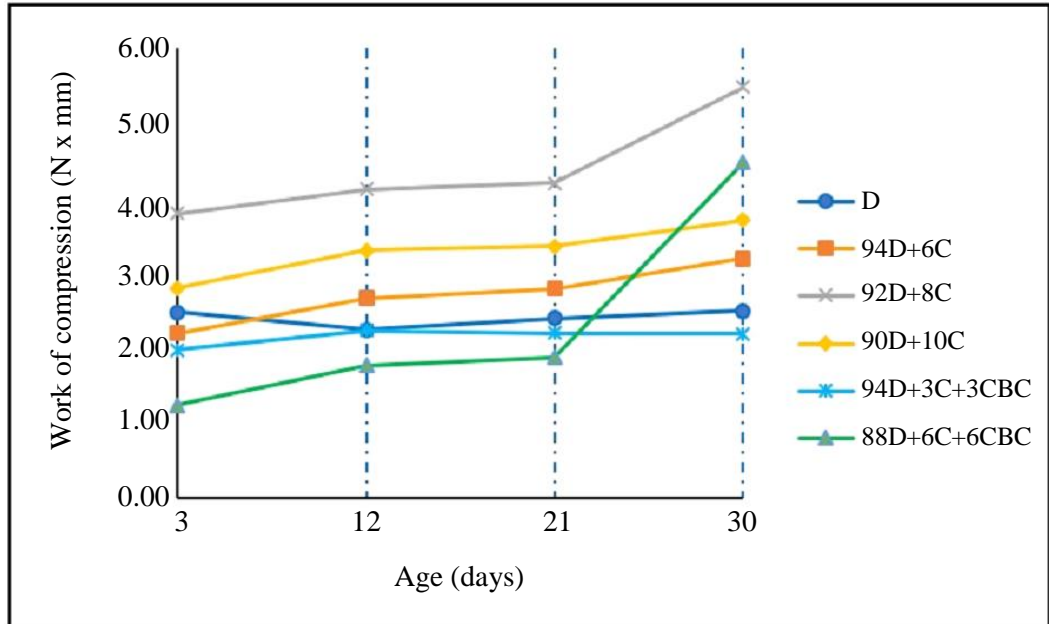

Fig. 8: Summary of estimation of the WOC for all GMs

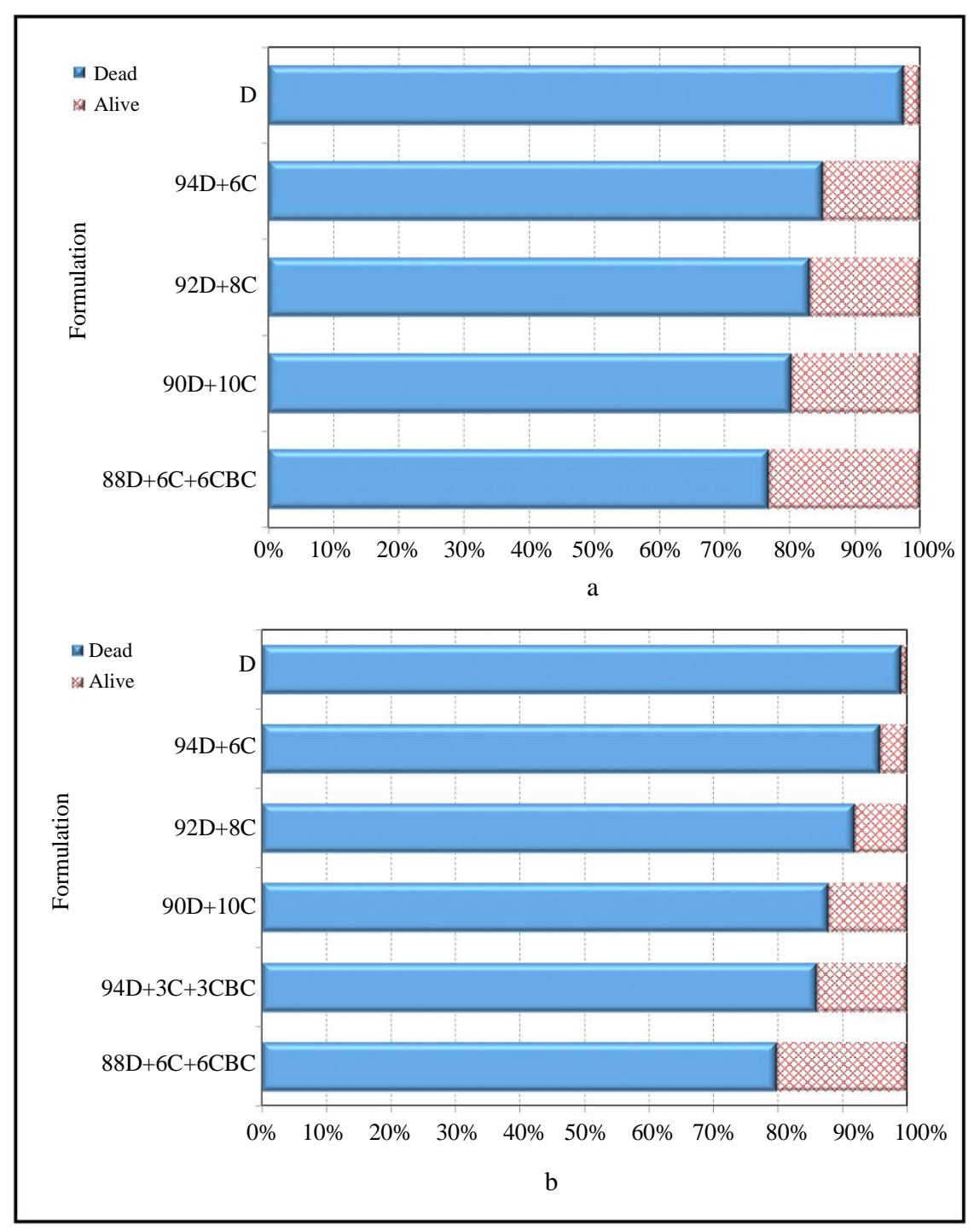

Fig. 9: Survival rate 


\section{Estimation of the EPN Survival Rate (SR)}

In Fig. 9a the results of the SRs of EPN estimated at 21 days are presented and analyzed. The pellets manufactured with only the $\mathrm{D}$ formulation had the lowest SR value (2\%). The addition of $\mathrm{C}$ improved by $15 \%$ the SR of EPN encapsulated in pellets prepared with only the $\mathrm{D}$ formulation. The SRs for the formulations containing C plus SCBA were higher by $24 \%$ with respect to the D formulation.

In Fig. 9b the results of the SRs of EPN estimated at 30 days are presented. At this age, the pellets manufactured with only the D had again the lowest SR $(1 \%)$. The addition of C improved only by 7\% the SR of EPN encapsulated in pellets prepared with only the D formulation. The SRs for the formulations containing $\mathrm{C}$ plus SCBA were higher by $16 \%$ with respect to the $\mathrm{D}$ formulation. These results motivate to carry out a second stage of the project applying the product obtained in corn fields.

Results show that the SRs decreased from 21 to 30 days. Results also confirm that the amount and type of granular material added to the different formulations had significant beneficial effects $(\mathrm{X} 2=490.7$ and Log-Rang $<0.001$ at 21 days and X2 $=474.3$ and Log-Rang $<0.001$ at 30 days) on the SR of the EPN (Steneirnema glaseri).

\section{Discussion}

The improvement of the strength of the GMs can be explained by the incorporation of additives to the raw materials. D exhibit an important amorphous halo which indicates the reactivity of some phases of the materials; when combined with alkali-rich materials, such as calcium hydroxide, they can be used to produce stronger cementitious materials (Bahurudeen et al., 2015). The combination of materials of different chemical and physical characteristics contribute to improving the adhesion and bond between the solid particles' surfaces. When granular materials are used, the surface area, density, porosity and shape of the particles play a significant role in the agglomeration process because such properties define the adherence and cohesion of the particles (Mort, 2005). The adherence and cohesion between particles greatly contribute to improving the mechanical strength of the GMs.

The GMs prepared with D show the tendency to decrease their axial compressive strength with time. Amorphous silica can react with $\mathrm{C}$ to form cementitious compounds which help to make the GM more stable. However, the presence of carbon can limit the forming of these cementitious compounds (Millogo et al., 2008).

This is caused by the loss of cohesion between particles. The cohesion between D particles is the result of their surrounding film of water, which causes the existing electrostatic forces and hydrogen bonds to keep the particles together when the material is moist (Skubiszewska-Zieba et al., 2012). When the material loses water, the cohesion decreases, promoting the separation of the D particles (Pimraksa and Chindaprasirt, 2009). The loss of strength of these GMs by dispersion of the particles disfavors the survival of the EPN. In consequence, the low SR of the EPNs encapsulated in the GM prepared by $\mathrm{D}$ can be attributable to the low moisture content at 21 and 30 days.

The GMs prepared with $\mathrm{D}+\mathrm{C}$ showed an increase in strength with time because the addition of $\mathrm{C}$ to a natural pozzolan (D) improves the mechanical properties of the latter (Vachón and Chulia, 1999). Other factors responsible for the improvement of the strength of the GMs are the surface area, the porosity and the alkalinity of the materials in this formulation (Maina and Barawa, 2011). The $\mathrm{D}$ particles can fix the $\mathrm{Ca} 2+$ ions because of their large surface area, leading to the formation of cementitious products. For this reason, the proportion of $\mathrm{D}$, in general, determines the quantity of siliceous compounds available for the pozzolanic reaction with $\mathrm{C}$ (Karatepe et al., 2004) and forms calcium silicoaluminates, especially $\mathrm{Ca}-\mathrm{Al}_{2}$ de $\mathrm{Si}_{4} \mathrm{O}_{12} .2 \mathrm{H}_{2} \mathrm{O}$ (Maina and Barawa, 2011; Karatepe et al., 1998). This reaction depends on the quantity of reactants available until reaching a point where the $\mathrm{C}$ available reacts with all the siliceous compounds (Martirena et al., 1998; Frías et al., 2011). Pozzolanic reactions occur at different stages, causing changes in the microstructures (Ogawa et al., 1980) by reducing with time the pore size in the GMs. The $\mathrm{C}$ added to $\mathrm{D}$ contributes to keeping the $\mathrm{D}$ particles together and preventing the loss of moisture; in consequence, the SR of EPN encapsulated in GMs prepared with these formulations increases when the dosage of $\mathrm{C}$ is higher.

The GMs prepared with the D+C+SCBA combinations showed the tendency to increase strength over time. The GMs prepared with 3\% SCBA show higher strength when compared to GMs prepared with only D; however, the strength was lower than estimated for GMs prepared with $\mathrm{D}+\mathrm{C}$. The increase in strength can be attributed to the formation of C-S-H type cementitious products (Sun et al., 2013; Maina and Barawa, 2011; Kastis et al., 2006), which are mostly the result of the beginning of the reaction between the $\mathrm{C}$ and the amorphous silica in the D.

At 30 days, the formulation with $6 \%$ SCBA increases its strength and overcomes the strength of the formulations with $\mathrm{D}+\mathrm{C}$. The increase in strength of the GMs prepared with $88 \mathrm{D}+6 \mathrm{C}+6 \mathrm{SCBA}$ when compared to those prepared with $\mathrm{D}+\mathrm{C}$ can be explained by the hydrophilic properties of SCBA (OH group at $3000 \mathrm{~cm}-1$ band). The D quickly absorbs water and forms liquid connections; however, the different particle sizes of the D can lead to the particles' segregation; therefore, solid connections cannot immediately be formed when $\mathrm{C}$ is added. Groups Al-OH, Al-S and Si-O (Quartz) favour the pozzolanic reaction (Frías et al., 2011). Nevertheless, it has been reported that the reactive capacity of the 
SCBA depends on the hydration conditions and chemical composition (Karatepe et al., 1998). This improvement can be observed at later ages. The higher SR of EPN encapsulate in these GMs can be the result of the hydrophilic properties of the SCBA which keep moisture for the survival of the EPN; however, this property of the SCBA could diminish the beneficial agglomerating effect of the $\mathrm{C}$ in the mixture.

The SCBA in combination with other materials helped to improve the EPN SR most likely because of its hydrophilic properties which keep the moisture in the GM a longer period of time as compared to the other formulations. It is very interesting to know the results that are obtained when these granular matrices are evaluated in corn fields

It can be said that the additives used in the elaboration of MGs to house the NEPs protected them against environmental stress. This result agrees with the observation by He et al. (2015); Wu et al. (2012).

\section{Conclusion}

The addition of $\mathrm{C}$ and SCBA to the $\mathrm{D}$ for the manufacture of GMs contributes to increasing its compressive strength. GMs prepared with $\mathrm{D}+\mathrm{C}$ show higher strength than those containing SCBA.

Age positively affects the increase of strength of the GMs prepared with $\mathrm{D}+\mathrm{C}$ and $\mathrm{D}+\mathrm{C}+\mathrm{SCBA}$.

The addition of $\mathrm{C}$ and SCBA to the $\mathrm{D}$ for the manufacture of GMs increases the EPN survival rate.

GMs prepared with the combination $88 \% \mathrm{D}+6 \% \mathrm{C}+6 \% \mathrm{SCBA}$ have the appropriate mechanical strength for handling and transport and the highest survival rates of $20 \%$ at 30 days.

Furthermore, the recycling of sugarcane bagasse ash waste in GMs shows highly positive results in terms of environmental protection and management practices.

\section{Acknowledgment}

The authors thank the Universidad Autónoma del Estado de Hidalgo (UAEH) and the Faculty of Civil Engineering of the UAEH (FIC-UAEH), as most of the testing was carried out at this institution.

\section{Funding Information}

The authors are grateful for the financial support of the Consejo Nacional de Ciencia y Tecnología of Mexico (CONACyT), the Instituto Politécnico Nacional of Mexico (IPN), COFAA-IPN, the PIFICOFAA-IPN Program and CIIDIR-IPN-Oaxaca.

\section{Author Contributions}

The authors contributed equally to this work.

\section{Ethics}

This article is original and contains unpublished material. The corresponding author confirms that all of the other authors have read and approved the manuscript and no ethical issues involved.

\section{References}

Alavéz-Ramírez, R., P. Montes-García, J. MartínezReyes, D.C. Altamirano-Juárez and Y. Gochi-Ponce, 2012. The use of sugarcane bagasse ash and lime to improve the durability and mechanical properties of compacted soil blocks. Constr. Build. Mater., 34: 296-305. DOI: 10.1016/j.conbuildmat.2012.02.072

Antonyuk, S., J. Tomas, S. Heinrich and L. Morl, 2005. Breakage behavior of spherical granulates by compression. Chem. Eng. Sci., 60: 4031-4044. DOI: $10.1016 /$ j.ces.2005.02.038

ASAE, 1993. ASAE S368.3 MAR95. Compression Test of Food Materials of Convex Shape. In: ASAE Standards, ASAE, St. Joseph, Michigan, Ch. S368.2, pp: 451-455.

ASTM, 2012. ASTM C618- $12^{\text {a }}$ Standard specification for coal fly ash and raw or calcined natural pozzolan for use in concrete.

Bahurudeen, A., D. Kanraj, V.G. Dev and M. Santhanam, 2015. Performance evaluation of sugarcane bagasse ash blended cement in concrete. Cement Concrete Comp., 59: 77-88. DOI: 10.1016/j.cemconcomp.2015.03.004

Batra, V.S., S. Urbonaite and G. Svensson, 2008. Characterization of unburnt carbon in fly ash bagasse. Fuel, 87: 2972-2976. DOI: 10.1016/j.fuel.2008.04.010

Bedding, R.A. and K.L. Butler, 1994. Method for storage of insecticidal nematodes. World Patent WO 94/05150.

Bika, D.G., M. Gentzler and J.N. Michaels, 2001. Mechanical properties of agglomerates. Powder Technol., 117: 98-112. DOI: $10.1016 / \mathrm{S} 0032-5910(01) 00318-7$

Chargas-Cordeiro, G., R.D. Toledo-Filho, L.M. Tavares and E.M. Rego-Fairbairn, 2009. Ultrafine grinding of sugar cane bagasse ash for application as pozzolanic admixture in concrete. Cement Concrete Res., 39: 110-115.

DOI: $10.1016 /$ j.cemconres.2008.11.005

Chen, S. and I. Glazer, 2005. A novel method for longterm storage of the entomopathogenic nematode Steinernema feltiae at room temperature. Biol. Control, 32: 104-110.

DOI: 10.1016/j.biocontrol.2004.08.006

Connick, W.J., W.R. Nickle, K.S. Williams and B.T. Vinyard, 1994. Granular formulations of Steinernema carpocapsae (strain All) (Nematoda: Rhabditida) with improved shelf life. J. Nematol., 26: 352-359. 
Coury, J.R. and M.L. Aguiar, 1995. Rupture of dry agglomerates. Powder Technol., 85: 37-43.

DOI: $10.1016 / 0032-5910(95) 03000-Y$

Driemeier, C., M.M. Oliveira, F.M. Mendes and E. O. Gómez, 2011. Characterization of sugar cane bagasse powders. Powder Technol., 214: 111-116. DOI: 10.1016/j.powtec.2011.07.043

Espinosa, R.M., 2005. Design of a machine to encapsulate entomopathogenic nematodes. MSc Thesis, Universidad Autónoma Chapingo, México.

Frías, M., E. Villar and H. Savastano, 2011. Brazilian sugar cane bagasse ashes from the cogeneration industry as active pozzolans for cement manufacture. Cement Concrete Comp., 33: 490-496. DOI: 10.1016/j.cemconcomp.2011.02.003

Ganesan, K., K. Rajagopal and K. Thangavel, 2007. Evaluation of bagasse ash as supplementary cementitious material. Cement Concrete Comp., 29: 515-524. DOI: 10.1016/j.cemconcomp.2007.03.001

García-Lara, S.D. and D. J. Bergvinson, 2007. Integral program to reduce post-harvest losses in corn. Agricultura Técnica en México, 33: 181-189.

Gauter, R., 2002. Entomopathogenic Nematology. 1st Edn., CABI Publishing, New York, ISBN-10: 0851995675, pp: 373.

Girón, P.S., 2008. Evaluation of two formulations of entomopathogenic nematodes to control white grub (Phyllophaga vetula) in maize. MSc Thesis, Instituto Politécnico Nacional CIIDIR-Oaxaca, Mexico.

Grewal, P.S., 2002. Formulation and Application Technology. In: Entomopathogenic Nematology, Gaugler, R. (Ed.), CABI, Wallingford, pp. 288-304.

He, Y., Z. Wu, L. Tu, Y. Han and G. Zhang et al., 2015. Encapsulation and characterization of slow-release microbial fertilizer from the composites of bentonite and alginate. Applied Clay Sci., 109-110: 68-75. DOI: 10.1016/j.clay.2015.02.001

Hiltpold, I., B.E. Hibbard, B.W. French and T.C.J. Turlings, 2012. Capsules containing entomopathogenic nematodes as a Trojan horse approach to control the western corn rootworm. Plant Soil, 358: 11-25. DOI: 10.1007/s11104-012-1253-0

Galal Morsy, H.E.M.B., 2010. Diatomaceus: Its characterization, modifications and applications. Asian J. Mater. Sci., 2: 121-136. DOI: 10.3923/ajmskr.2010.121.136

Imbert, C. and M.V. Villar, 2006. Hydro-mechanical response of a bentonite pellets/powder mixture upon infiltration. Applied Clay Sci., 32: 197-209.

DOI: 10.1016/j.clay.2006.01.005

Karatepe, N., N. Erdogan, A. Ersoy-Mericboyu and S. Küçübayrak, 2004. Preparation of diatomite/Ca $(\mathrm{OH}) 2$ sorbents and modelling their sulphation reaction. Chem. Eng. Sci., 59: 3883-3889.

DOI: $10.1016 /$ j.ces.2004.04.013
Karatepe, N., A. Ersoy-Mericboyu, U. Demirler and S. Kücükbayrak, 1998. Determination of the reactivity of $\mathrm{Ca}(\mathrm{OH}) 2$-fly ash sorbents for $\mathrm{SO}_{2}$ removal from flue gases. Thermochimica Acta, 319: 171-176. DOI: 10.1016/S0040-6031(98)00400-6

Kastis, D., G. Kakali, S. Tsivilis and M.G. Stamatakis, 2006. Properties and hydration of blended cements with calcareous diatomite. Cement Concrete Res., 36: $1821-1826$.

DOI: 10.1016/j.cemconres.2006.05.005

Kaya, H.K. and S.P. Stock, 1997. Techniques in Insect Nematology. In: Manual of Techniques in Insect Pathology, Lacey, L.A. (Ed.), Academic Press, Klein, San Diego, CA, pp: 281-324.

Kaya, H.K., C.M. Mannion, C.M. Burlando and C.E. Nelsen, 1987. Escape of Steinernema feltiae from alginate capsules containing tomato seeds. J. Nematol., 19: 287-291.

Liu, Y., D. Scharf, T. Graule and F. J. Clemens, 2014. Granulation processing parameters on the mechanical properties of diatomite-based porous granulates. Powder Technol., 263: 159-167. DOI: 10.1016/j.powtec.2014.04.094

Maina, P. and M. Barawa, 2011. Enhancement of lime reactivity by addition of diatomite. Fuel Process. Technol., 92: 1910-1919.

Malhotra, V.M. and A.A. Ramezanianpour, 1994. Fly Ash in Concrete. 1st Edn., Canada Centre for Mineral and Energy Technology (CANMET), Ottawa, Ontario, Canada, ISBN-10: 0-660-157640, pp: 307.

Martirena, J.F., B. Middendorf, M. Gehrke and H. Budelmann, 1998. Use of wastes of the sugar industry as pozzolana in lime-pozzolana binders: Study of the reaction. Cement Concrete Res., 28: 1525-1536. DOI: 10.1016/S0008-8846(98)00130-6

Matadamas-Ortiz, P.T., J. Ruiz-Vega, J.A. VázquezFeijoo, H. Cruz-Martínez and C.I. Córtes-Martínez, 2014. Mechanical production of pellets for the application of entomopathogenic nematodes: Factors that determine survival time of Steinernema glaseri. Biocontrol Sci. Technol., 24: 145-157. DOI: $10.1080 / 09583157.2013 .852161$

Mendoza, P.M., 2012. Effect of pellet hardness on the mortality of mechanically encapsulated entomopathogenic nematode Steinernema glaseri. MSs Thesis, Instituto Politécnico Nacional CIIDIROaxaca, Mexico.

Millogo, Y., M. Hajjaji and R. Ouedraogo, 2008. Microstructure and physical properties of limeclayey adobe bricks. Constr. Build. Mater., 22: 2386-2392.

DOI: 10.1016/j.conbuildmat.2007.09.002

Mort, P.R., 2005. Scale-up of binder agglomeration processes. Powder Technol., 150: 86-103. DOI: $10.1016 /$ j.powtec.2004.11.025 
Navon, A., S. Keren, L. Salamae and Y. Glazer, 1998. An edible-to-insects calcium alginate gel as a carrier for entomopathogenic nematodes. Biocontrol Sci. Technol., 8: 429-437.

DOI: $10.1080 / 09583159830225$

Navon, A., D.K. Nagalakshmi, S. Levski, L. Salame and I. Glazer, 2002. Effectiveness of entomopathogenic nematodes in an alginate gel formulation against lepidopterous pests. Biocontrol Sci. Technol., 12: 737-746. DOI: 10.1080/0958315021000039914

NIMF, 2005, Directrices para la exportación, el envío, la importación y liberación de agentes de control biológico y otros organismos benéficos [Guidelines for the export, shipment, import and release of biological control agents and other beneficial organisms]. FAO.

NOM-021-SEMARNAT, 2000. Especificaciones de fertilidad, salinidad y clasificación de suelos. Estudios, muestreo y análisis [Specifications of fertility, salinity and soil classification. Studies, sampling and analysis].

Ogawa, K., H. Uchikawa, K. Takemoto and I. Yasui, 1980. The mechanism of the hydration in the system C3S-pozzolana. Cement Concrete Res., 10: 683-696. DOI: 10.1016/0008-8846(80)90032-0

Petersen, J.J. and O.R. Willis, 1972. Procedures for the mass rearing of a mermithid parasite of mosquitoes. Mosquitoes News, 32: 226-230.

Pimraksa, K. and P. Chindaprasirt, 2009. Lightweight bricks made of diatomaceous earth, lime and gypsum. Ceram. Int., 35: 471-478.

DOI: $10.1016 /$ j.ceramint.2008.01.013

Silver, S.C., D.B. Dunlop and D.I. Grove, 1995. WIPO patent No. WO 95/0577. World Intellectual Property Oerganization, Geneva.
Skubiszewska-Zieba, J., B. Charmas, R. Leboda and V.M. Gun'ko, 2012. Carbon-mineral adsorbents with a diatomaceous earth/perlite matrix modified by carbon deposits. Microporous Mesoporous Mater., 156: 209-216.

DOI: $10.1016 /$ j.micromeso.2012.02.038

Sun, Z., X. Yang, G. Zhang, S. Zheng and R.L. Frost, 2013. A novel method for purification of low grade diatomite powders in centrifugal fields. Int. J. Mineral Process., 125: 18-26.

DOI: $10.1016 /$ j.minpro.2013.09.005

Umamaheswaran, K. and V.S. Batra, 2008. Physicochemical characterization of Indian biomass ashes. Fuel, 87: 628-638. DOI: 10.1016/j.fuel.2007.05.045

Vachón, M.G. and D. Chulia, 1999. The use of energy indices in estimating powder compaction functionality of mixture in pharmaceutical tableting. Int. J. Pharmaceut., 177: 183-200. PMID: 10205613

Wen-Tien, T., L. Chi-Wei and H. Kuo-Jong, 2006. Characterization and adsorption properties of diatomaceous earth modified by hydrofluoric acid etching. J. Colloid Interface Sci., 297: 749-754. DOI: $10.1016 /$ j.jcis.2005.10.058

Wen-Tien, T., H. Kuo-Jong and L. Chi-Wei, 2004. Chemical activation of spent diatomaceous earth by alkaline etching in the preparation of mesoporous adsorbents. Industrial Eng. Chem. Res., 43: 7513-7520. DOI: 10.1021/ie0400651

Wu, Z.S., L.N. Guo, S.H. Qin and C. Li, 2012. Encapsulation of R. planticola Rs-2 from alginatestarch-bentonite and its controlled release and swelling behaviour under simulated soil conditions. J. Industrial Microbiol. Biotechnol., 39: 317-327. DOI: $10.1007 / \mathrm{s} 10295-011-1028-2$ 